\title{
YOUTH THRIVE: A FRAMEWORK TO HELP ADOLESCENTS OVERCOME TRAUMA AND THRIVE
}

\author{
Charlyn Harper Browne \\ Center for the Study of Social Policy \\ Susan Notkin \\ Center for the Study of Social Policy
}

\author{
Andrew Schneider-Muñoz \\ The Protean Institute for Economic and Intergenerational Development
}

\section{Francie Zimmerman}

Center for the Study of Social Policy

\section{Youth Thrive Origins and Framework}

Helping youth realize their dreams while also keeping them safe and attending to their physical and emotional needs is the goal for all parents. Balancing dreams and needs also defines the role of those working with youth in the child welfare system. In 2011, the Center for the Study of Social Policy (CSSP) began an effort to reverse the troubling outcomes that many young people in the foster care system experience (Courtney, 2009) and to capitalize on the inherent strengths that exist in these youth. CSSP is a national nonprofit organization dedicated to improving life chances for our country's most vulnerable children, youth, and families and has a long history of working with child welfare systems to produce better results. CSSP's interest in creating a youth development agenda coincided with several other important changes: breakthroughs in the field of adolescent brain development, the passage of the federal Fostering Connections to Success and Increasing Adoptions Act ${ }^{1}$ in 2008, and the federal call for child welfare agencies to elevate their focus on child and youth well-being, in addition to safety and permanency.

Recently there has also been a growing belief in communities and among child welfare and youth services experts as to the value of practitioners dealing with both risk factors that compromise a child's life prospects (e.g., family violence) and protective and promotive factors (e.g., resilience, social connections) that minimize risk and advance well-being (Epstein, 2004). By drawing attention to the importance of balancing attention to risk reduction with that of the promotion of health, the Youth Thrive Framework is consistent with the tenets

1 This federal law promotes permanent families for children and youth in foster care through relative guardianship and adoption, as well as improving education and health care services, extending federal support for youth to age 21, increasing opportunities for success when youth leave care, and providing federal protections and support to American Indian children. 
of positive youth development that recognizes that "problem-free does not mean fully prepared" (Pittman, 1992, p. 1). This article describes CSSP's Youth Thrive protective and promotive factors framework and examines how a focus on thriving is necessary to complement the growing interest in being trauma-informed.

This article describes CSSP's Youth Thrive protective and promotive factors framework and examines how a focus on thriving is necessary to complement the field's growing move to become trauma-informed. Previous efforts to identify protective factors targeted the developmental needs of the youngest children, up to six years old, aiming to help parents to promote the healthy development of their children (Horton, 2003). Youth Thrive posits a research-informed framework for building protective and promotive factors for adolescents and young adults, ages 9-26 years old, particularly the most vulnerable youth (Harper Browne, 2014).

The Youth Thrive framework is based on what the research on resilience, positive youth development, neuroscience, and trauma indicates contributes to healthy development and well-being and reduces the impact of traumatic and negative life experiences for all youth. The research led to the identification of five protective and promotive factors that mitigate risk and promote well-being, as well as the concomitant critical outcomes that constitute healthy adolescent development. The Youth Thrive protective and promotive factors ${ }^{2}$ are:

- Youth Resilience: Managing stress and functioning well when faced with stressors, challenges, or adversity; building on individual characteristics, strengths, and interests.

- Social Connections: Having healthy, sustained relationships with people, institutions, the community, and a force greater than oneself that promote a sense of trust, belonging, and that one matters.

- Knowledge of Adolescent Development: Understanding the unique aspects of adolescent development including information on adolescent brain development and the impact of trauma; implementing developmentally and contextually appropriate best practices.

- Concrete Support in Times of Need: Understanding the importance of asking for help and advocating for oneself; receiving quality services (e.g., health care, housing, education) designed to preserve youths' dignity, provide opportunities for skill development, and promote healthy development.

- Cognitive and Social-Emotional Competence: Acquiring skills and attitudes (e.g., executive functioning, character strength, future orienta-

2 For more information on the Youth Thrive protective and promotive factors go to http://www.cssp. org/reform/child-welfare/youth-thrive 
tion, persistence, and positive emotions) that are essential for forming an independent identity and having a productive, responsible, and satisfying adulthood (Harper Browne, 2014, p. 3).

The Youth Thrive Framework provides a roadmap for workers, foster parents, managers, and administrators to operationalize the somewhat amorphous concept of "well-being" for youth in foster care or who have experienced abuse, neglect, or other adverse experiences. By being deliberate and intentional about building these protective and promotive factors in their everyday encounters with the youth they support, youth workers can increase the likelihood of making significant, positive differences in the lives of youth resulting in improved outcomes.

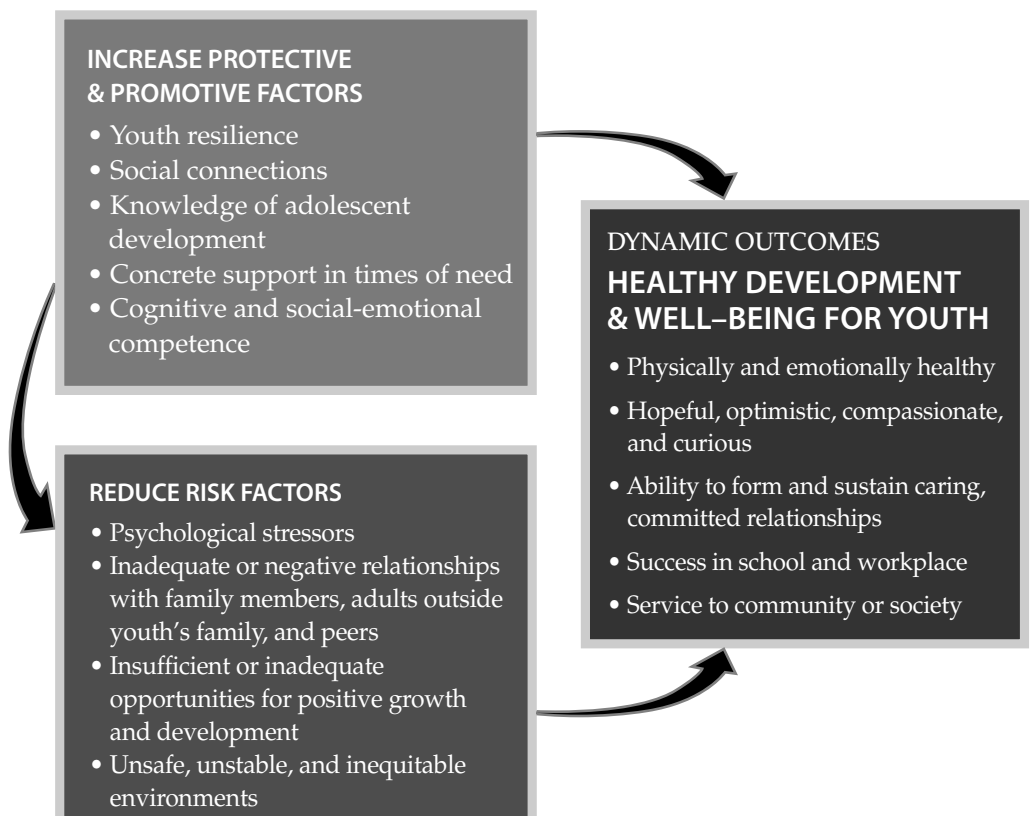

Figure 1: Youth Thrive Framework (Center for the Study of Social Policy, 2013)

\section{Trauma and Adolescence}

During adolescence the brain experiences a great wave of growth and development, second only to the rapid development that occurs during the first years of life (Siegel, 2013). Despite the acknowledged impact of trauma on brain development, this new research also suggests that positive experiences and opportunities can help create new neural pathways, build new brain architecture, and help youth heal from trauma and grow into mature, successful adults (Shonkoff \& Garner, 2012). 
All youth have stressful experiences from time to time. In fact, exposure to experiences that create mild or positive stress is considered necessary for healthy development because youth have "the opportunity to learn how to effectively manage stress, regulate emotions, and develop the social, behavioral, and cognitive coping resources needed to overcome these obstacles" (Gunnar, Herrera, \& Hostinar, 2009, p. 4). Youth need to learn to cope with stressful situations, such as experiencing failure, in order to be fully prepared for adulthood (Harper Browne, 2014).

However, someyouth are faced with extremely intense stressful experiencestraumatic events—such as being in a serious car accident, being abused by a caretaker, or witnessing violence in their neighborhood. It is estimated that $26 \%$ of American children will witness or experience a traumatic event before the age of four (Briggs-Gowan, Ford, Fraleigh, McCarthy, \& Carter, 2010). The National Child Traumatic Stress Network (NCTSN) states, "Children who suffer from child traumatic stress are those children who have been exposed to one or more traumas over the course of their lives and develop reactions that persist and affect their daily lives after the traumatic events have ended" (2003, p. 1).

According to the NCTSN (n.d.), traumatic events can be differentiated by the duration of the event and classified as "acute" or "chronic" trauma. Acute traumatic experiences (e.g., school shootings, death of a loved one)"occur at a particular time and place and are usually short-lived" (NCTSN, n.d., para. 1). Chronic traumatic experiences (e.g., recurring sexual or physical abuse, persistent neglect, family violence) "occur repeatedly over long periods of time" (NCTSN, n.d., para. 3). Both types of traumatic experiences can cause immediate and enduring negative biological, psychological, and behavioral effects; the effects of trauma on early brain development, in particular, can be significant.

When faced with any type of stressful event, the brain automatically triggers the body's stress response system, which is a series of physical changes such as increased heart rate, blood pressure, and production of stress hormones. Traumatic experiences create an intense and sustained activation of the body's stress response system, referred to as "toxic stress" (Middlebrooks \& Audage, 2008; Shonkoff \& Garner, 2012). "Extensive research on the biology of stress now shows that healthy development can be derailed by excessive or prolonged activation of stress response systems in the body and the brain, with damaging effects on learning, behavior, and health across the lifespan" (National Scientific Council on the Developing Child, 2005/2014, p. 1). Several damaging effects of toxic stress on early brain development that, without intervention, can become most evident during adolescence have been identified by researchers (see, e.g., Jim Casey Youth Opportunities Initiative, 2011; Langford \& Badeau, 2013; Lupien, McEwen, Gunnar, \& Heim, 2009; National Scientific Council on the Developing Child, 2005/2014). They include: 
- Development of a smaller brain

- Low threshold for stress that results in being overly reactive to upsetting, challenging, or adverse experiences

- Difficulty managing stressful situations

- Difficulty regulating emotions and being emotionally attuned to others

- Heightened fear, anxiety, and impulsive responses

- Difficulty relating to other people and forming healthy relationships

- Cognitive deficits such as impaired reasoning, planning, and behavior control

- Suppressed immune system causing vulnerability to chronic health problems (Harper, 2014)

Pynoos and colleagues (2007) assert that one critical outcome of traumatic experiences is the formation of trauma-related expectations:

By their very nature and degree of personal impact, traumatic experiences can skew [youths'] expectations about the world ... These expectations ... shape concepts of self and others and lead to forecasts about the future that can have a profound influence on current and future behavior (Pynoos et al., p. 332).

The effects of traumatic experiences are further exacerbated when youth have complex trauma histories. Complex trauma refers to "the dual problem of exposure to multiple traumatic events and the impact of this exposure on immediate and long-term development" (Jim Casey Youth Opportunities Initiative, 2011, p. 13). For example, many youth in out-of-home-care endure the trauma that led to the removal from their home, the trauma of being separated from their families, and the additional trauma of multiple removals and placements (Bruskas, 2008; Frerer, Sosenko, \& Henke, 2013; Hieger, 2012). "Children exposed to complex trauma often experience lifelong problems that place them at risk for additional trauma exposure and cumulative impairment (e.g., psychiatric and addictive disorders; chronic medical illness; legal, vocational, and family problems)" (Cook et al., 2005, p. 390).

Although research has shown that exposure to traumatic experiences can interfere with healthy development and well-being, this does not mean negative outcomes are inevitable, even when children and youth experience complex trauma (Cook et al., 2005; Easterbrooks, Ginsberg, \& Lerner, 2013; Jim Casey Youth Opportunities Initiative, 2011; Middlebrooks \& Audage, 2008; Runyan et al., 2014). 
Research has also shown, "even when stress is toxic, supportive parenting, positive peer relationships, and the availability and use of community resources can foster positive adaptation" (Easterbrooks et al., 2013, p. 102). That is, youth can learn to demonstrate resilience and to thrive when supported by trusted, nurturing, competent, and caring adults who offer positive guidance; provide opportunities for productive decision-making and constructive engagement in various social contexts; and promote the development of self-regulation, self-reflection, self-confidence, self-compassion, and character (Harper Browne, 2014; Jim Casey Youth Opportunities Initiative, 2011).

Bundick and colleagues (2010) delineated five core principles of thriving, based on a review of theoretical and empirical literature about this construct:

1. Thriving is an essentially developmental construct, which entails a general orientation toward and, over time, the realization of relatively stable movement along an upward (though perhaps nonlinear) life trajectory.

2. Thriving focuses on aspects of development beyond merely the absence of the negative, and beyond mere competence or simple achievement of developmental tasks - in this way, we might think of thriving as a theory of optimal development (not just adequate development).

3. Thriving refers to the functioning of the integrated, whole person across all life domains; thus, the term implies personal balance, such that one is not considered to be thriving if he or she is functioning and developing positively in one aspect or area of his or her life.

4. Thriving recognizes the multidirectional nature of relations between person and context, through which both the individual and his or her contexts are mutually enhanced. This notion of mutual enhancement implies a moral component of thriving - when thriving, individuals act on (and thus help create) their environments, they seek to in some way contribute to others and/or the multiple ecologies in which they are embedded.

5. Thriving entails the engagement of one's unique talents, interests, and/ or aspirations. In this lies the assumption of one's self-awareness of his or her uniqueness, and the opportunities to purposefully manifest them. Through such engagement, one might be thought of as actively working toward fulfilling his or her full potential (pp. 891-892).

\section{Youth Work to Address Trauma and Promote Thriving}

At its founding and to this day, child and youth care work has maintained two central themes: (a) a focus on understanding and changing behavior and (b) using the activities of everyday life to model social skills and competencies (Stuart, 2012). Child and youth care work has increasingly focused on delivering 
activities that build core competencies that are at the heart of the Youth Thrive framework. Youth workers seek to understand the meaning behind risk and organize daily life events as a milieu to demonstrate and teach youth to avoid unhealthy risks and cultivate protective factors that contribute to healthy behavior (Garfat, Fulcher, \& Digney, 2013).

Given their frequent contact and often close relationships with young people, youth workers are in an opportune position to promote positive change over time. Youth workers take responsibility for what is commonly called "the other 23 hours" - that is all of the time outside the dedicated therapy hour during which social and emotional growth occurs (Brendtro, Whittaker, \& Trieschman, 1969). During these hours, youth workers encounter the majority of the effects associated with youth who have experienced trauma. Trauma-informed approaches enable youth workers to utilize brain-based, neuroscience research to effectively address the neural changes associated with repeated exposures to trauma.

In order to effectively teach youth how to reprogram responses that have been shaped by past trauma, youth workers must be knowledgeable about brain development during adolescence and the effects of trauma on relationships and other aspects of a youth's life. For example, youth workers need to know that the adolescent brain develops unevenly; that is, different parts mature at different rates. The structures and functions in the limbic system that contribute to emotionssuch as fear, anger, and pleasure-develop in early adolescence, but structures and functions in the prefrontal cortex - the area of the brain responsible for effective decision making, controlling impulses, and balancing risks and rewards-are still evolving well into early adulthood (Jim Casey Youth Opportunities Initiative, 2011). This imbalance can explain much of the perplexing, inconsistent, and at times problematic behavior typical to most adolescents. It is also important to be aware that the brain continues to strengthen the neural pathways that are used most frequently (Siegel, 2013). It is absolutely critical to recognize that since young adults' brains and their cognitive functions are still developing, all older youth deserve access to opportunities for positive youth development and a second chance (and sometimes additional chances) if necessary. In fact, these scientific insights should become a mandate for practice and policy (Samuels \& Blitz, 2014).

Through repeated healthy experiences and activities organized by the youth worker, the brain can develop healthier patterns and behaviors based on positive interactions. Daily life events also provide repeated opportunities for youth to negotiate the practical challenges of relationships and effectively incorporate what they learn from the adults providing direct care. By being intentional about what the research says youth need in order to thrive and using trauma-informed approaches over time, workers can help youth build the protective and promotive factors that are associated with the dynamic outcomes of healthy development and well-being.

Mealtimes, sports, school, afterschool, and community service are all contexts in which youth workers can reduce risk and increase protective and promotive 
factors by teaching youth healthy, appropriate behaviors for lifelong success in the community, at home, and eventually at work. In these venues and through these activities, youth workers can give youth opportunities to take reasonable risks and have new adventures, experiences, and challenges (e.g., through creative, artistic, academic or athletic pursuits; travel; acquisition of new skills) that adolescents seek but without the risk of potentially overwhelming negative consequences (e.g., from delinquency, high risk sexual behavior, drug abuse). Through these experiences, youth have the opportunity to develop a multitude of peer and adult relationships they can call upon and count on in difficult times. The network of peer relationships are equally important, as adults help youth foster friendships and engage in healthy, age-appropriate activities. In addition, youth can learn how to manage stress effectively, ask for help, and advocate for themselves-mastering core competencies associated with healthy development and well-being.

\section{Implementation of the Youth Thrive Framework}

While a conceptual framework that synthesizes new information is helpful, the promise of better outcomes for individuals and better performance for systems and services can only be realized if the framework is put into action. Towards that end, Youth Thrive provides a perspective or lens that can be used to examine and modify frontline practice, policy, organizational culture, and infrastructure. Over the past two years, CSSP has worked to further develop and implement the Youth Thrive Framework specifically with youth involved in the child welfare system.

CSSP is currently developing and piloting a variety of tools and materials that support the implementation of Youth Thrive strategies in policy and practice. For example, the National Resource Center for Youth Services (at the University of Oklahoma) and the Academy for Competent Youth Work have developed a Youth Thrive training curriculum. This training focuses on understanding the five protective and promotive factors and explores how outcomes can be improved by using Youth Thrive ideas to change direct practice. Units of the curriculum set the stage to fully explore the dynamics of the youth-adult partnership with the purpose of building strengths and reducing risk. Participants engage in interactive exercises to practice new skills that can be used in everyday interactions to reduce stress and promote practical problem solving.

Youth Thrive is also working with select jurisdictions. The State of New Jersey, under the leadership of the Department of Children and Families' Office of Adolescent Services has launched a comprehensive Youth Thrive initiative. The Commissioner established a new task force with the charge to review and make changes at every level in the delivery of services to older youth based on the Youth Thrive framework. Called the Task Force on Helping Youth Thrive in Placement (HYTIP), this cross-functional team is working to successfully change contracting and licensing language to reflect the critical implementation of protective and promotive factors. HYTIP is also working to better articulate the role of resource 
and treatment homes in placing youth on the pathway to lifelong resilience. This translates into practical and critical efforts such as listening and acting on the recommendations of Youth Boards; preparing Youth Thrive guides for youth, parents, and staff; and shifting the process of preparing for transitioning out of care to better reflect normal adolescent healthy growth and development (Task Force on Helping Youth Thrive in Placement, n.d.).

Youth Thrive is also working with the Brevard Family Partnership, a community-based organization that delivers child welfare services in Brevard County, Florida. The Brevard Family Partnership's adoption of the Youth Thrive Framework complements the State's agenda to create "normalcy" in the lives and experiences of all youth in Florida's foster care system. While the New Jersey experience represents the power of what a government jurisdiction can do to better guide every service, policy, and practice to result in resilience for youth, Brevard County represents the potential of a community-driven approach for helping youth in care to thrive.

The Partnership has brought together a roundtable of representatives from the different sectors serving adolescents. In Brevard, a trauma-informed care youth summit was launched in which more than 400 leaders across the community have twice gathered to respond to the youth's recommendations of what they need to succeed and thrive. This community café dialogue was led by successful young leaders who grew up in foster care. It resulted in action steps to be pursued through the system of care including service providers, churches, government leaders, educators, business executives, and other stakeholders. The Youth Thrive committee meets on a monthly basis to identify and implement ways in which policies and practices within the region can adopt the protective and promotive factors framework. The committee's goal is to engage the whole community in helping youth to manage risk and move towards resilience.

\section{Youth Thrive Search for Exemplary Initiatives}

During 2014, CSSP conducted a national search to identify and recognize initiatives that are robust exemplars of programs, policies, services and advocacy efforts that operationalize the Youth Thrive protective and promotive factors. The purpose of the search was multifaceted: to increase awareness and understanding of the Youth Thrive approach; to strengthen the case for this approach by providing tangible, on-the-ground examples; to learn about and share effective strategies; and to identify and build a national network of skilled practitioners and leaders committed to the healthy development and well-being of adolescents.

CSSP invited nominations for initiatives that work with youth involved in the child welfare system (i.e., foster care, prevention, or postplacement services) and that explicitly address the protective and promotive factors. Additional selection criteria for the exemplary initiatives included the following: be innovative and go beyond the basics to do something exceptional; employ a strengths-based 
approach; develop and maintain systems and infrastructure that support the initiative (e.g., hiring, training, supervision, data collection and analysis, quality improvement); be attuned to the needs of diverse racial and ethnic groups and to LG$\mathrm{BTQ}^{3}$ populations; and assess impact on youth and show evidence of effectiveness.

The search began with an open, online request for nominations that CSSP widely distributed to individuals and networks familiar with youth-serving programs. Nominated programs went through an extensive application and rigorous review process which included submitting detailed written information, a telephone interview, a site visit, and interviews with youth, families, and staff. The search was conducted by CSSP staff and consultants. An expert panel-with expertise in youth development, child welfare, public policy, research, and traumainformed care-provided guidance on the search process. Youth advisors served on the panel, and young leaders with experience in the child welfare system participated as part of the review team on the site visits.

Out of an initial pool of more than 130 nominations, CSSP recognized 15 exemplary initiatives. These initiatives represent a variety of organizations-public and nonprofit, service providers and advocacy efforts, community-based providers, and large multi-state programs. They employ a wide variety of strategies and engage in diverse activities - all with a shared goal of improving outcomes for youth who have been involved in the child welfare system. The range of selected initiatives include: a statewide youth advisory board; programs implementing aggressive strategies to ensure youth have lasting, positive connections to family; universities providing scholarships and campus-based support for former foster youth; educational champions advocating for individual students and improvements in public education systems; training for staff working with pregnant and parenting teens; and a neighborhood center with employment, recreation, and supportive services for youth in foster care.

\section{Trauma-Informed Practice and Attention to Thriving}

All of the Youth Thrive exemplary initiatives are aware of the growing importance of recognizing and understanding trauma, and many have incorporated aspects of trauma-informed care into their work with youth. For several of the initiatives, addressing trauma is fundamental to their philosophy and a hallmark of their approach. Their specific strategies are powerful illustrations of how youthserving organizations and youth workers can put a trauma-informed orientation into action. These initiatives combine attention to trauma with a vital commitment to promoting adolescents' well-being in order to help youth truly thrive.

Based in Milwaukee, SaintA is an organization that provides foster care, mental health, and education services. It is in the forefront of understanding the impact of trauma on the developing brain and changing policy and practice to reflect that

3 Lesbian, gay, bisexual, transgender, and questioning populations. 
understanding. An essential first step in that shift is changing attitudes and reframing the conversation with youth from: "What is wrong with you?" to "What happened to you and how can I support you?" In collaboration with Dr. Bruce Perry, of the Child Trauma Academy, and Dr. Robert Anda, co-investigator on the Adverse Childhood Experiences Study (ACE), SaintA is integrating trauma-informed practice into all of its services.

SaintA uses Perry's Neurosequential Model of Therapeutics (Perry \& Hambrick, 2008) and other tools to examine youth's history and current functioning. It utilizes these assessments to understand an individual's trauma experiences and the impact on their physical and emotional development. With this information, SaintA staff determine appropriate interventions to mitigate past trauma and re-evaluate interventions over time. In terms of treatment, SaintA customizes therapeutic responses for each youth's experience and often uses sensory-based interventions - such as yoga, drumming, singing, knitting, and physical activities such as dance or horseback riding - that address lower brain function. These types of rhythmic, repetitive activities help calm the brain and support self-regulation. This is an important distinction from other more traditional treatment interventions that typically focus on cognitive or executive tasks that constitute upper parts of brain function.

Cultivating calm, close relationships between family members, staff, and youth is central to SaintA's work to ensure that all understand the impact of past trauma and are ready to help youth heal and thrive. SaintA staff pay particular attention to ensuring a good fit with foster families and building caregiver capacity to establish safe environments and consistent relationships. It is an agency priority to keep youth within their communities and schools so that the trauma of being removed from their family is not further exacerbated by additional disruptions.

A powerful indication of SaintA's commitment to being trauma-informed throughout its operations is that all staff-not just direct service workers but also janitorial, kitchen, administrative, and managerial employees—attend training to understand trauma and its impact on youth and families. This training process transforms how employees view their work. For example, maintenance staff have a different insight into why a young person might damage property. SaintA has also incorporated trauma-informed commitments into all job descriptions and created a culture where interactions with the children, youth, and families are empathic and consistent with the overall mission of the organization. The agency's goal is to support youth to heal from the trauma they experienced and, as one youth served by SaintA, said,"Be in a situation where you can move forward with all the tools you need."

In addition to reforming all of its own internal operations, SaintA is conducting training and building networks to spread trauma-informed care throughout the state of Wisconsin including training for schools to become trauma-sensitive. Its goal is to educate other human service professionals and community members to understand the ingredients of trauma-informed care. They have reached over 10,000 practitioners to date. 
Another powerful example of trauma-informed work is at Anu Family Services (Anu). In 2006, Anu set an ambitious goal: to be the last placement prior to permanence for $90 \%$ of the youth they serve. That year, $38 \%$ of youth leaving Anu's foster care services were discharged to a permanent placement. By the end of 2012, that percentage had almost doubled to 70\% (according to Anu Family Services Performance Measures for 2012). Anu's work is based on two key beliefs: (a) youth's past trauma, grief, and loss must be addressed in order for youth to form lasting, meaningful relationships and (b) the search for people who youth have loved and lost should be extensive and exhaustive.

Guiding all of Anu's work is the conviction that youth are the boss of the process. Youth have the right to hire and fire their caseworker and determine the pace and content of the work such as who to reach out to and when. Anu is determined to help youth progress from writhing to surviving to thriving. In helping youth address and confront grief, loss, and trauma and navigate the complexities of establishing relationships with adults, Anu Family Services empowers youth to tackle their own personal struggles in a supportive environment. Anu has documented its approach in a comprehensive, clear guidebook that addresses trauma-effective practice strategies with many relevant tools and graphics (Jones, LaLiberte, \& Meyer, 2013).

Difficult to capture in writing is the intensity and urgency that Anu brings to its work with youth. It is not satisfied with typical service or system responses to youth that too often pathologize their behavior, readily medicate them, and react to difficulties by moving youth to new and often more restrictive placement settings-severing relationships and retraumatizing them.

The trauma compounds, and the youth have no safe place to express their intensive grief and loss or to process their trauma. Still, we continue to blame the youth for their behaviors, which are the result of trauma which we have either inflicted and/or failed to heal. We know more than we have ever known before about the impact of trauma, but we still have entire public and private systems that do not fully understand and, therefore, do not practice, trauma-informed care. Once we know better, we must do better (Jones et.al., 2013, p. 2).

Working in Minnesota and Wisconsin, Anu's permanence specialists carry small caseloads (8 or less) and use a variety of exercises (e.g., timelines, connection maps, permanency pacts) to help youth identify, strengthen, and maintain supportive relationships with adults. It employs evidence-informed practices such as the 3-5-7 Model developed by Darla Henry (Henry, 2012) which is comprised of three tasks, five questions, and seven skills to help youth understand their past, grieve losses, and prepare for permanence. Beyond the goal of permanence, Anu has adopted a four part model of well-being that is comprised of:

- using trauma-informed parenting

- building networks of support and connection 
- addressing grief, loss, and trauma

- engaging in interactive healing interventions (Anu Model of Wellbeing, 2014)

Anu coaches customize services to each individual family and teach caregivers methods and tools they can use with youth to promote attachment, self-esteem, and the development of positive behaviors. In partnership with the Center for Spirituality and Healing at the University of Minnesota, Anu employs techniques not traditionally used in child welfare, such as mindfulness-based stress reduction, yoga, and equine therapy. These activities give youth the opportunity to engage in activities-other than formal counseling or talk-based therapies-that can enhance their well-being.

Another avenue for addressing trauma is through the arts. In Jacksonville, Florida, Family Support Services of Northern Florida, Inc., a large, comprehensive child welfare agency, engages youth in creative and performing arts to deal with past trauma and express who they have been, who they are, and who they want to become. At its three week summer camp called Just Like Me, youth are given complete creative license to follow their interest and write, sing, dance, paint, or make videos that tell their own stories. Just Like Me was designed for youth who are involved in the foster care system to help them develop their artistic talents and gain skills such as trust, teamwork, problem solving, and decision-making. Local professional artists lead classes in drama, dance, singing, songwriting, rap, spoken word, creative writing, photography, and visual arts.

Just Like Me intentionally serves the highest risk youth (e.g., youth who have been kicked out of placements, have mental health or substance abuse problems, and are victims of human trafficking). It targets young people who are not likely to be selected or participate in other academic, sports, or enrichment activities. During the camp, mental health counselors are available to help youth handle any issues that surface during the creative process. Each young artist leaves with a product of their work and participates in a culminating performance for an enthusiastic audience of family, foster parents, staff, media, and community members.

Through creative expression, Just Like Me helps youth in foster care recognize and capitalize on their strengths, acknowledge their challenges, manage adversity, and heal from the effects of trauma. Through intensive team-building activities, the youth increase their self-esteem and improve their communication and conflict resolution skills. Participants gain new social networks-of mentors, artists, and peers - that help youth develop a sense of connectedness, greater self-confidence, and personal responsibility. Youth also gain information about future education and career opportunities that use artistic and creative talents. Many camp participants maintain relationships with artists, agency staff, and other participants and return to participate in activities throughout the year.

Operating in 12 California counties, Seneca Family of Agencies (Seneca) is 
another strong example of how trauma-informed strategies and a focus on thriving and resiliency are embedded within an organization's culture, policies, and clinical practice. Unconditional Care, as both a philosophy and treatment model, is the foundation and core conceptualization of all Seneca services delivered to youth and families referred by the child welfare, behavioral health, juvenile justice, and special education systems. As a philosophy and approach, Unconditional Care is reflected in numerous practical ways, including being available to families at the times and places that are most convenient for them, 24 hours/seven days a week; utilizing evidence-based and evidence-informed intervention strategies to garner the best possible outcomes; ensuring that every child leaves our care with a viable and sustainable permanency plan and relentlessly pursuing engagement even when initial attempts fail or falter. Indicative of Seneca's philosophy is its commitment to never discharge a young person for exhibiting the behavior that brought them to Seneca in the first place (Sprinson \& Berrick, 2010).

In order to expand and strengthen the protective and promotive factors for vulnerable youth and their families, Seneca's Unconditional Care treatment model integrates three approaches to assessment and intervention: relational, behavioral, and ecological. The relational approach, grounded in attachment theory, assumes that effective intervention requires defining each young person's internal working model(s) and identifying specific and intentional ways of responding that do not reinforce his/her maladaptive internal schema of relationship. The behavioral approach, based upon social learning theory, focuses on modifying the settings and antecedents associated with troubling behaviors, as well as teaching more adaptive replacement behaviors through positive behavioral intervention. Ecological assessment and intervention, drawn from ecological systems theory, seeks to leverage resources and strengths in the family system to meet the child and family's unmet needs (Sprinson \& Berrick, 2010), and ensure the family has a sustainable and enduring network of supports and permanent connections at the time of transition.

Offering a somewhat different perspective on the issue of trauma is the My Life Project, based at Portland State University in Oregon. The My Life Project works with youth who are preparing to exit the child welfare system. While staff are trained in understanding the impact of trauma on brain development, staff at this program do not read a youth's case record nor ask or expect a youth to talk about past experiences. Thus, they do not necessarily identify or address youth's past trauma explicitly. Coaches focus on helping youth set their own goals and solving problems identified and defined by young people themselves. My Life interventions entail learning and practicing key strategies such as requesting help and taking action.

My Life's guiding principle is self-determination, helping young people learn how to direct their own lives. Their work is founded on the premise of "nothing about me without me." In keeping with that commitment, youth themselves determine if and when they want to share their histories. In most instances, youth do choose to share their stories with My Life staff. My Life staff report that youth 
greatly appreciate that staff get to know them first without any preconceived notions or judgments based on their past. The My Life Project is currently conducting a randomized control trial of its intervention and already has evidence of successful outcomes for the self-determination approach. A prior randomized study with a sample of 69 youth was conducted on the TAKE CHARGE model, the intervention on which the My Life Project is based. Serving youth who were in both foster care and special education, the evaluation found moderate to large effects post-intervention and at one year follow-up for youth who participated in the TAKE CHARGE intervention, specifically positive differences in self-determination, quality of life, and utilization of community transition services. Youth in the intervention group also completed high school, were employed, and carried out independent living activities at notably higher rates than the comparison group (Powers et al., 2012).

\section{Conclusion}

The momentum within the children's and youth service community toward becoming trauma-informed is a welcomed step toward helping youth who have had adverse experiences heal. Even while recognizing how difficult this system transformation will be, attention must not stop at helping youth to survive their past and make sense of their history. Rather efforts aimed at healing need to be combined with work that help youth identify, uncover, and build on their strengths, and ultimately thrive. Doing so requires intentional attention toward building and maintaining the protective and promotive factors that research indicates are associated with healthy adolescent development and well-being.

To ensure that workers, managers, and leaders are committed to helping youth to heal and to thrive, consider the following:

Choosing the workforce. Quality work obviously starts with clarity about the kinds of staff agencies want working with youth. Workers can be taught skills but they cannot be taught values. At a very basic level, youth workers have to like adolescents, enjoy working with them, and believe in their potential. They need to embody a strengths-based approach and be in the business of building hope. Staff who understand that they are in the business of building hope are better equipped to know how to listen and encourage dreams.

Training and supporting the workforce. Creating the kind of workforce required to help youth thrive necessitates training, supervision, accountability, and resources that reinforce a culture of high expectations. It involves ensuring that the policies that guide everyday interactions with youth and that provide the foundation upon which services are delivered are informed by adolescent brain development, the impact of trauma on development, and what youth need to flourish. Workers need both skills and support in helping young people to overcome their history and their trauma while not being defined by that history or trauma. Building on and nurturing youth's best qualities, instead of fixating on 
their worst traits, is not an easy task. Staff need help in order to assist youth to learn from and even use their lived experiences to overcome adversities. Such an orientation will enable workers to help youth tap into those very qualities that are too often overlooked, or even identified and condemned as part of the youth's problem behavior.

Discovering new service strategies. Agencies need to reexamine their old tool boxes of services and interventions and incorporate some newer models of interventions that are proving useful, not only in addressing trauma but instilling core competencies of self-regulation, executive functioning, and resilience. Such interventions include everything from neurosequencing to play to yoga to music and mindfulness. And services need to be developmentally appropriate for different chronological and developmental age groups. Agencies and organizations should also consider using validated trauma screening and assessment tools. The National Child Traumatic Stress Network has developed a searchable database containing reviews of measures important for screening and assessing children exposed to traumatic stress. ${ }^{4}$

Developing a youth thriving trauma-informed policy agenda. Policies and programs need to facilitate youth participation in activities that promote normalcy. For example, going on sleepovers, participating in afterschool sports and music programs, attending college tours are all activities that youth who are not in foster care take for granted. We need to ensure that youth in care are exposed to the same types of enrichment activities. Agencies also need to reexamine their policies around critical incidents and rewards and punishments so that greater restrictions are not automatically imposed on youth for acting like typical adolescents. Restricting contact with families should never be used as a punishment for acting out behavior.

Engaging and partnering with youth. Services need to be youth-driven. Youth need a voice in creating and driving their case plan based on their own dreams and aspirations for their future. The slogan, "Nothing about Us without Us," needs to define agency culture and practice. Beyond individual case planning, agencies and organizations can establish and support opportunities and forums for youth to take on leadership roles - weighing in on policy changes, governance issues, and decision-making functions that impact young people and their families.

In conclusion, just as parents have always tried to balance meeting both their children's needs and dreams so, too, do all those adults who work with children and youth in child welfare and other youth services. Youth workers can play a critical role in guiding youth's healing from trauma while also equipping them with the protective and promotive factors that will help them to truly thrive.

4 The database can be found at http://nctsn.org/resources/online-research/measures-review 


\section{References}

The Anu Model of WellBeing. Retreived August 4, 2014 from Anu Family Services website https://www.anufs.org/about_us/anu_model/

Brendtro, L. K. (2009). Deep brain learning: Pathways to potential with challenging youth. Michigan: Starr Commonwealth.

Brendtro, L. K., Whittaker, J. K., \& Trieschman, A. E. (1969). The other 23 hours: Child-care work with emotionally disturbed children in a therapeutic milieu. New Jersey: AldineTransaction.

Briggs-Gowan, M. J., Ford, J. D., Fraleigh, L., McCarthy, K., \& Carter, A. S. (2010). Prevalence of exposure to potentially traumatic events in a healthy birth cohort of very young children in the northeastern United States. Journal of Traumatic Stress, 23, 725-733.

Bruskas, D. (2008). Children in foster care: A vulnerable population at risk. Journal of Child and Adolescent Psychiatric Nursing, 21(2), 70-77.

Bundick, M. J., Yeager, D. S., King, P. E., \& Damon, W. (2010). Thriving across the life span. In W. F. Overton \& R. M. Lerner (Eds.), The handbook of life-span development (pp. 882-923). Hoboken, NJ: John Wiley \& Sons, Inc.

Center for the Study of Social Policy. (2015). Youth Thrive ${ }^{\mathrm{TM}}$. Retrieved from Author http://www.cssp.org/reform/child-welfare/youth-thrive

Cook, A., Spinazzola, J., Ford, J., Lanktree, C., Blaustein, M., Cloitre, M., .. . van der Kolk, Bessel. (2005). Complex trauma in children and adolescents. Psychiatric Annals, 35(5), 390-398.

Courtney, M. E. (2009). The difficult transition to adulthood for foster youth in the US: Implications for the state as coporate parent. Social Policy Report, 23(1), 3-19.

Easterbrooks, M. A., Ginsberg, K., \& Lerner, R. M. (2013, Fall). Resilience among military youth. The Future of Children, 23(2), 99-120. Retrieved from http:// www.futureofchildren.org/futureofchildren/publications/docs/Chapter\%205.pdf

Epstein, M. H. (2004). Behavioral and Emotional Rating Scale: A strength-based approach to assessment, Examiner's Manual $2^{\text {nd }} e d$. Austin, TX: PRO-ED. 
Frerer, K., Sosenko, L. D., \& Henke, R. R. (2013, March). At greater risk: California youth and the path from high school to college. San Francisco, CA: Stuart Foundation. Retrieved from http://www.stuartfoundation.org/docs/defaultdocument-library/at-greater-risk-california-foster-youth-and-the-pathfrom-high-school-to-college.pdf?sfvrsn=6

Garfat, T., Fulcher, L., \& Digney, J. (2013). Making moments meaningful in child and youth care practice. Cape Town, South Africa: Pretext Publishing.

Gunnar, M. R., Herrera, A., \& Hostinar, C. E. (2009). Stress and early brain development. Encyclopedia on Early Childhood Development. Retrieved from http://www.ccl-cca.ca/pdfs/ECLKC/encyclopedia/Enc09_Gunnar-HerreraHostinar_brain_en.pdf

Harper Browne, C. (2014). Youth Thrive: Advancing healthy adolescent development and well-being. Retrieved from Center for the Study of Social Policy: http://www.cssp.org/reform/child-welfare/youth-thrive/2014/Youth-Thrive_ Advancing-Healthy-Adolescent-Development-and-Well-Being.pdf

Henry, D. (2012). The 3-5-7 Model: A Practice approach to permanence. Camp Hill, PA: Sunbury Press, Inc.

Hieger, J. (2012, December). Post-traumatic stress disorder and children in foster care: Information packet. New York, NY: National Resource Center for Permanency and Family Connections. Retrieved from http://www.nrcpfc.org/is/ downloads/info_packets/PTSDandChildren_in_FC.pdf

Horton, C. (2013). Protective factors literature review: Early care and education program and the prevention of child abuse and neglect. Retrieved from http://www. cssp.org/reform/strengthening-families/resources/body/LiteratureReview. $\mathrm{pdf}$

Jim Casey Youth Opportunities Initiative. (2011). The adolescent brain: New research and its implications for young people transitioning from foster care. St. Louis, MO: Jim Casey Youth Opportunities Initiative.

Jones, A., LaLiberte, T., \& Franck Meyer, A. (2013). Creating a permanency driven organization: A Guidebook for change in child welfare. Anu Family Services. Retrieved from https://www.anufs.org/assets/forms/AnuGuide.pdf 
Langford, B. H., \& Badeau, S. (2013, August). A plan for investing in the social, emotional, and physical well-being of older youth in foster care: Connected by 25. Retrieved from http://www.fostercareworkgroup.org/media/resources/ FCWG_Well-Being_Investment_Agenda.pdf

Lupien, S. J., McEwen, B. S., Gunnar, M. R., \& Heim, C. (2009, June). Effects of stress throughout the lifespan on the brain, behavior, and cognition. Naturn Reviews Neuroscience, 10, 434-445. Retrieved from www2.charite-psychiatrie.de/fileadmin/pdf/lehre/2009_2010/psy/Effects_of_Stresss_..._-_Lupien_et_al._2009_02.pdf

Mattingly, M., Stuart, C., \& Vander Ven, K., (2002). Competencies for professional youth work practitioners. Journal of Child and Youth Care Work, 17, 16-49.

Middlebrooks, J. S., \& Audage, N. C. (2008). The effects of childhood stress on health across the lifespan. Atlanta, GA: Centers for Disease Control and Prevention, National Center for Injury Prevention and Control.

The National Child Traumatic Stress Network. (2003). What is child traumatic stress? Retrieved from Author http://www.nctsnet.org/sites/default/files/assets/pdfs/what_is_child_traumatic_stress_0.pdf

The National Child Traumatic Stress Network. (n.d.). Defining trauma and child traumatic stress. Retrived from Author http://www.nctsnet.org/content/ defining-trauma-and-child-traumatic-stress

National Scientific Council on the Developing Child. (2005/2014). Excessive stress disrupts the architecture of the developing brain. Working Paper No. 3. Updated Edition. Retrieved from http://www.developingchild.harvard.edu/index.php/ resources/reports_and_working_papers/working_papers/wp3/

Perry, B. D., \& Hambrick, E. P. (2008). The neurosequential model of therapeutics. Retrieved from http://www.scribd.com/doc/15622954/Introduction-to-theNeurosequential-Model-of-Therapeutics

Pittman, K. (1992, Sept./Oct.). Let's make youth work a field. Youth Today. Retrieved from http://forumfyi.org/files/Youth\%20Today--September-October\%201992.pdf 
Powers, L., Geenen, S., Powers, J., Pommier-Satya, S., Turner, A., Dalton, L., ... Swank, P. (2012). My Life: Effects of a longitudinal, randomized study of self-determination enhancement on the transition outcomes of youth in foster care and special education. Child and Youth Services Review, 34, 2179-2187.

Pynoos, R. S., Steinberg, A. M., \& Goenjian, A. (2007). Traumatic stress in childhood and adolescence: Recent developments and current controversies. In B. A. van der Kolk, A. C. McFarlane, \& L. Weisaeth (Eds.), Traumatic stress: The effects of overwhelming experience on mind, body, and society (331-358). New York, NY: Guilford Press.

Runyan, D., English, D., Litrownik, A., Dubowitz, H., Kotch, J., \& Thompson, R. Ensuring safety, well-being and permance for our children: Findings, practice and policy implications from LONGSCAN. Retrieved from http://www.unc.edu/ depts/sph/longscan/pages/DDCF/LONGSCAN\%20Science\%20to\%20Practice.pdf

Samuels, B., \& Blitz, C. (2014). A call to action: Promoting effective inerventions for children in child welfare using neuroscience. Social Policy Report, 28, 28-31.

Siegel, D. (2013). Brainstorm: The power and purpose of the teenage brain. New York, NY: Jeremy P. Tarcher/Penguin.

Shonkoff, J. P., \& Garner, A. S. (2012). The lifelong effects of early childhood adversity and toxic stress. Pediatrics, 126, 232-246. Retrieved from http://www. pediatrics.aappublications.org/content/129/1/e232.full.pdf

Sprinson, J., \& Berrick, K. (2010). Unconditional care. New York, NY: Oxford University Press.

Stuart, C. (2012). Foundations of child and youth care work. Dubuque, IA: Kendall Hunt Publishing.

Task force helping youth thrive in placement. (n.d.). Retrieved August 7, 2014 from http://www.nj.gov/dcf/adolescent/TaskForceHYTIP.pdf 